Journal of Applied Pharmaceutical Science Vol. 2 (9), pp. 155-157, September, 2012

Available online at http://www.japsonline.com

DOI: $10.7324 /$ JAPS.2012.2930

ISSN 2231-3354 (cc) BY-NC-SA

\title{
Self Monitoring of Blood Pressure(SMBP) among Hypertensive patients in Muscat- A pilot study
}

\author{
Dunia Al Hadithi, Abdul Salam Nazmi* and Shah Alam Khan \\ Dept of Pharmacy, Oman Medical College, Muscat, Sultanate of Oman.
}

\section{ARTICLE INFO}

Article history:

Received on: 07/09/2012

Accepted on: 20/09/2012

Available online: 28/09/2012

Key words:

Hypertension,

Self monitoring of blood

pressure, Sphygmomanometer,

Blood pressure

\begin{abstract}
Monitoring of blood pressure (BP) is an important aspect of the diagnosis and management of hypertension. SMBP of patients at home can provide patients and physicians with valuable information in the management of hypertension. The aim of this pilot study was to determine the prevalence of SMBP among primary care hypertensive patients in Muscat region and to assess their practices and attitude towards SMBP. The study was conducted in two phases. In the first phase 126 patients visiting primary health care centers or polyclinics in Muscat region were interviewed to identify patients who practice SMBP. In the second phase a closed ended questionnaire containing 10 questions related to demographic characteristics, practice and attitude was self administered to 50 patients enrolled from the first phase to generate the data. It was found that around $40 \%$ of the patients use Sphygmomanometer to monitor their BP at home. However, majority of the patients were aware of the significance and importance of BP home monitoring and therefore, recommended the practice of SMBP to other hypertensive patients. Participants acknowledged the role of pharmacist in educating and training the patient about the proper use of BP measuring device. Patients were convinced with the device performance but at the same time the frequency of BP monitoring was poor among the participants. Overall the participants had a positive attitude towards SMBP but the frequency of BP monitoring was poor among the participants and had a room for the improvement. There is a need to aware and educate the Omani hypertensive patients about the importance of SMBP to achieve the desired therapeutic goals. SMBP may be a valuable tool in hypertension self-management, therefore, clinicians should consider recommending it more widely.
\end{abstract}

\section{INTRODUCTION}

Hypertension (HTN), a silent disease, is a major public health problem affecting more than 1 billion individuals worldwide (Chobanian et al., 2003). It is a chronic medical condition in which the blood pressure is elevated. According to World Health Survey data of 2008, the community prevalence of HTN in Sultanate of Oman was estimated to be $40 \%$ (Al Saadi et al., 2011). Monitoring of blood pressure (BP) is an important aspect of the diagnosis and management of HTN. Self-monitoring

\footnotetext{
* Corresponding Author
}

Dr. Abdul Salam Nazmi

Dept of Pharmacy, Oman Medical College, PO Box 620

Postal code 130, Muscat, Oman, Tel: 00968-24504608 (195) of BP by patients at home is one strategy by which hypertensive patients can participate in the management of their own disease and possibly help them cope with the disease. SMBP leads to small but significant reductions in blood pressure (Fahey et al., 2005). SMBP may increase adherence to pharmacological and non pharmacological interventions and may decrease the incidence of fatal diseases such as stroke, myocardial infarction, heart failure, renal dysfunction etc. The World Health Organization -International Society of Hypertension Guidelines proposes use of self measurement of BP at home as an important means to evaluate the response to antihypertensive treatment, to improve compliance with therapy and most importantly, as an alternative for ambulatory BP 
measurement to confirm or refute the diagnosis of white coat hypertension (Chalmers et al., 1999). The aim of this study was to determine the prevalence of self monitoring of BP in primary care hypertensive patients in Muscat region and to evaluate the characteristics of those that Self-monitor blood pressure.

\section{METHODS}

A close ended questionnaire was developed to assess the practice and attitude of hypertensive patients in Muscat governorate of Sultanate of Oman. It was validated for accuracy, language clarity, readability and length by administering it to 5 patients. Patients were assessed with self administered questionnaire to obtain information about their age, gender, performance of BP measuring device and practice regarding SMBP.

A total of 126 patients, 18 years or older attending various primary health centers or polyclinics in Muscat region were identified. After obtaining the approval from the health centre administration, 126 patients were requested to answer a simple question 'Do you use a Home blood pressure monitoring device to check your blood pressure?' beside their age and gender. Only those patients who self monitored their BP at home were selected and enrolled for further study. The goal and objectives of the study were briefly explained to participants and a verbal consent was obtained. A total of 50 completely filled questionnaires were used to generate the data. The data was analyzed statistically by SPSS version 19.0.

\section{RESULTS AND DISCUSSION}

Initially 126 hypertensive patients were asked about SMBP practice and it was found that approximately $40 \%(n=50)$ of them use Sphygmomanometer to monitor their BP at home. There are few published reports on prevalence of SMBP to which we have compared our results. A study of hypertensive patients in a primary care clinic in Singapore found that $24 \%$ of hypertensives measure their BP at home (Tan et al., 2005). Another study conducted in Italy demonstrated that a much higher proportion $(66 \%)$ was using SMBP (Cuspidi et al., 2004).

Table. 1: Characteristics of respondents who Self monitor and do not self monitor BP $(\mathrm{n}=126)$.

\begin{tabular}{llll}
\hline \multicolumn{1}{c}{ Item } & \multicolumn{1}{c}{$\begin{array}{c}\text { Self Monitor } \\
\mathbf{B P}(\boldsymbol{\%})\end{array}$} & $\begin{array}{c}\text { Do not Self } \\
\text { monitor BP }(\boldsymbol{\%})\end{array}$ & $\begin{array}{c}\text { Chi test-p } \\
\text { value }\end{array}$ \\
\hline Gender & & & \\
Male & $22(44)$ & $34(44.73)$ & \\
$\begin{array}{l}\text { Female } \\
\text { Total number }\end{array}$ & $28(56)$ & $42(55.26)$ & $0.935(\mathrm{NS}) *$ \\
$\begin{array}{l}\text { Age (in years) } \\
\text { Less than 50 }\end{array}$ & $24(48)$ & 76 & \\
Above 51 & $26(52)$ & $32(42.1)$ & $0.514(\mathrm{NS}) *$ \\
*NS- Non significant & $44(57.9)$ & \\
\hline
\end{tabular}

Out of 126 patients, $70(55.55 \%)$ were females and 56 $(44.45 \%)$ were males. No significant difference was observed when gender and age of the respondents who practice and do not practice SMBP respectively was compared (Chi test $\mathrm{p}$ value $=0.935$ and 0.514$)$. Out of 50 patients who monitor their BP level at home, $24(48 \%)$ were aged below 50 years and $52 \%$ were above 50 years respectively (Table-1).

Attitude and practices of 50 patients who monitor their BP were further evaluated by self administered questionnaire and the results are presented in table 2 . Overall, $44 \%$ male (95\% CI 30.2-57.8) and 56\% (95\% CI 42.2-69.8) female respondents reported currently using SMBP device at home. Majority (52\%) of the participants were aged above 50 years while only $10 \%$ of the total population were less than 29 years of age.

Despite clinical evidences that SMBP can assist in controlling BP in hypertensive patients, we found that only 21 Patients (42\%) were measuring their BP based on their physician's recommendation while 58\% were monitoring it as a simple desire. This reflects their positive attitude towards attaining hypertensive treatment goals and to reduce the risk of HTN related complications.

A total of 37 respondents (74\%) admitted having been explained the significance and instruction on the proper testing technique of the device by the pharmacist. Proper education is very important for SMBP, especially since there are varieties of sphygmomanometers available in market. Pharmacists can play an integral role in educating patients about the proper technique of these devices and appropriate times to measure BP.

$68 \%$ patients were using the device themselves to measure their BP suggests that these patients are highly aware and the devices are easy and simple to use. Approximately two third of the study population were satisfied with the performance of their device as it was easy to use and gave accurate results in few seconds. SMBP plays an important role in clinical intervention, therefore it is imperative that BP measuring devices must be easy to maneuver and its values are accurate and precise. The monitoring results also helped the patients to feel and recognize the sign and symptoms when BP level was high, low or normal. It is therefore; not surprising that majority of the participants (84\%) (95\% CI 73.8-94.2) would like to recommend the practice of SMBP to other hypertensive patients to understand and manage their disease better.

The result of this pilot study suggests that frequency of BP monitoring was poor among the participants. Majority of the $(62 \%)$ participants were irregular in monitoring their BP as they were measuring their BP only when they feel tired.

It was interesting to note that despite monitoring their BP at home, 58\% respondents did not write a chart of their measurement because their health care provider usually does not ask for the readings. $42 \%$ of the participants were providing the $\mathrm{BP}$ readings to adjust medication regimen. But at the same time, an equal no of participants were comparing their device reading with the clinical reading to rule out the possibility of white coat hypertension and to ensure that their device is functioning well. 
Table. 2: Attitude and practices of SMBP patients $(n=50)$.

\begin{tabular}{|c|c|c|c|c|}
\hline S. No & Variables & $\begin{array}{c}\mathrm{N}=50 \\
\text { Percent }\end{array}$ & Std Error & $95 \%$ Confidence interval \\
\hline \multirow[t]{3}{*}{1.} & Gender & & & \\
\hline & Male & 44 & 0.0702 & $30.24-57.75$ \\
\hline & Female & 56 & & $42.24-69.75$ \\
\hline \multirow[t]{4}{*}{2.} & Age (years) & & & \\
\hline & Less than 29 & 10 & 0.0424 & $16.84-18.31$ \\
\hline & $30-50$ & 38 & 0.0686 & 24.54- 51.45 \\
\hline & More than 50 & 52 & 0.0706 & $38.15-65.84$ \\
\hline \multirow[t]{3}{*}{3.} & Why do you measure BP? & & & \\
\hline & Doctor's recommendation & 42 & 0.0698 & $28.31-55.68$ \\
\hline & A simple desire to know your BP & 58 & & $44.31-71.68$ \\
\hline \multirow[t]{3}{*}{4.} & Did pharmacist teach you how to use it? & & & \\
\hline & Yes & 74 & 0.0620 & $61.84-86.15$ \\
\hline & No & 26 & & $13.84-38.15$ \\
\hline \multirow[t]{3}{*}{5.} & Who measure BP for you? & & & \\
\hline & Yourself & 68 & 0.0659 & $55.06-80.93$ \\
\hline & Someone else from family & 32 & & $19.06-44.93$ \\
\hline \multirow[t]{3}{*}{6.} & Are you convinced by the device and its performance? & & & \\
\hline & Yes & 60 & 0.0692 & $46.42-73.57$ \\
\hline & No & 40 & & $26.42-53.57$ \\
\hline \multirow[t]{3}{*}{7.} & How often do you measure your BP? & & & \\
\hline & Regularly & 38 & 0.0686 & 24.54-51.45 \\
\hline & Not regularly (Only when you feel tired) & 62 & & 48.54-75.45 \\
\hline \multirow[t]{3}{*}{8.} & Do you write a chart of your measurement? & & & \\
\hline & Yes & 42 & 0.0698 & $28.31-55.68$ \\
\hline & No & 58 & & $44.31-71.68$ \\
\hline \multirow[t]{3}{*}{9.} & Do you compare your device reading with clinical reading? & & & \\
\hline & Yes & 50 & 0.0707 & $36.14-63.85$ \\
\hline & No & 50 & & $36.14-63.85$ \\
\hline \multirow[t]{3}{*}{10.} & Would you recommend the device to other hypertensive patients? & & & \\
\hline & Yes & 84 & 0.0518 & 73.83-94.16 \\
\hline & No & 16 & & $5.83-26.16$ \\
\hline
\end{tabular}

\section{CONCLUSION}

The awareness and importance of home monitoring device for BP has increased substantially in recent years. In this pilot study, we found that approximately $40 \%$ of 126 hypertensive patients in primary care settings currently practice SMBP. Because SMBP may be a valuable tool in hypertension self-management, clinicians should consider recommending it more widely. Pharmacist can play an important role in Patient education to live a good productive life. By acquiring knowledge and suitable skills, patients will be able to learn how to cope with this chronic disease.

\section{ACKNOWLEDGEMENTS}

Authors would like to thank Dean, Assoc. Dean of Oman Medical College for providing necessary facilities and guidance to carry out this study.

\section{REFERENCES}

Chobanian AV, Bakris GL, Black HR, Cushman WC, Green LE, Izzo JL, et al. The Seventh Report of the Joint National Committee on Prevention, Detection, Evaluation, and Treatment of High Blood Pressure. JAMA. 2003; 289:2560-72.
Al Saadi R, Al Shukaili S, Al Mahrazi S, Al Busaidi Z. Prevalence of uncontrolled Hypertension in primary care settings in $\mathrm{Al}$ Seeb Wilayat, Oman.SQU Med J. 2011;11(3):349-356.

Fahey T, Schroeder K, Ebrahim S. Educational and organisational interventions used to improve the management of hypertension in primary care: a systematic review. British J Gen Prac. 2005; 55(520):875-882.

Chalmers J, MacMahon S, Mancia G, Whitworth J, Beilin L, Hansson L, Neal B, Rodgers A, Mhurchu CN, Clark T. World Health Organization International Society of Hypertension guidelines for the management of hypertension. J Hypertens. 1999; 17:151-183.

Tan NC, Khin LW, Pagi R. Home blood-pressure monitoring among hypertensive patients in an Asian population. J Hum Hypertens. 2005;19:559-564.

Cuspidi C, Meani S, Fusi V, et al. Home blood pressure measurement and its relationship with blood pressure control in a large selected hypertensive population. J Hum Hypertens. 2004;18:725-731.

\section{How to cite this article:}

Dunia Al Hadithi, Abdul Salam Nazmi and Shah Alam Khan. Self Monitoring of Blood Pressure (SMBP) among Hypertensive patients in Muscat- A pilot study. J App Pharm Sci. 2012; 2(9): 155-157. 